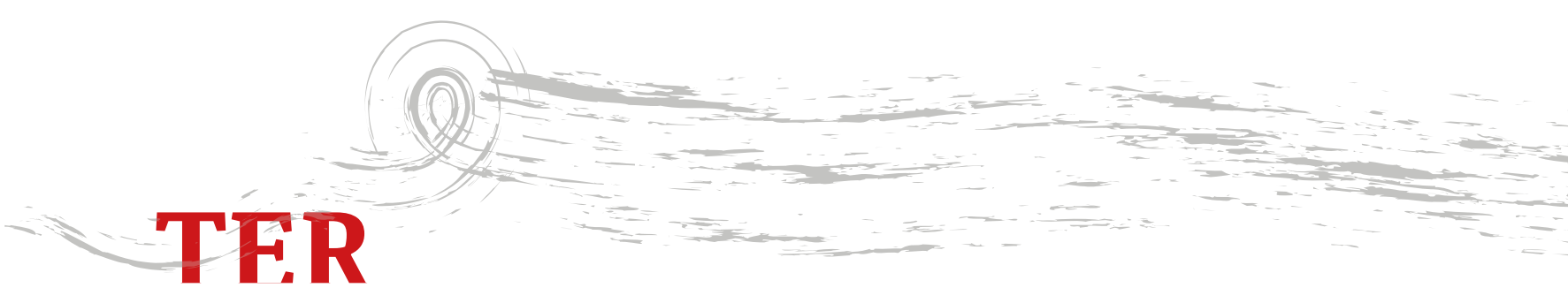

University College London,

CHRISTOPHER PINNEY

Londres, Reino Unido.

tradução

JANAÍNA SANT' ANA DE ANDRADE

revisão técnica

ANDRÉA BARBOSA

TRADUÇÃO

NOTAS DA SUPERFÍCIE

DA IMAGEM: FOTOGRAFIA, PÓS-COLONIALISMO

E MODERNISMO

VERNACULAR ${ }^{1}$

Como tradições visuais locais realizam uma mediação em relação a ideia de modernidade de maneiras que independem e criticam a modernidade europeia? Houston Baker, em Modernism and the Harlem Renaissance (1987), pergunta como alguém pode seriamente entender, por exemplo, W. E. B Du Bois ou Langston Hughes de uma maneira que não os caracterize (e os reduza) a serem "como" (ou "não como") T. S. Eliot ou Ezra Pound. O esforço de Baker é para se libertar do modelo de uma consciência e razão "Ocidental" soberana, do tipo que Dipesh Chakrabarty (2000) procura "provincializar" através da recuperação de práticas paralelas. Parte da solução de Houston Baker se encontra na ênfase na ideia de "deformação do domínio" $(1986,49)$ intrínseco à Harlem Renaissance, uma ideia desenvolvida por Homi Bhabha $(1994,241)$ em uma direção bastante diferente, sob a combinação do performativo/deformativo.

1. Este artigo foi originalmente publicado em: Pinney, Christopher, Peterson, Nicolas. 2003. Photography's Other Histories. Duhan: Duke University Press 
Uma ideia similar é explorada aqui: isto é, a maneira pela qual as tradições fotográficas locais criativamente deformam as espacializações geométricas de mundos coloniais. As práticas fotográficas pós-coloniais dão origem a um "modernismo vernacular; imagens que projetam uma materialidade da superfície, ou o que Olu Oguibe (1996) chama de "a substância da imagem". Nessas práticas, a superfície torna-se um local de recusa da profundidade que foi característica dos regimes de representação coloniais. "Superfície" e "profundidade" referem-se não simplesmente a camadas sedimentares, mas a posicionamentos mais profundos que fundem o ético/político com o cronotópico². 0 que poderia ser denominado de esquema "colonial" posicionava pessoas e objetos profundamente dentro de convicções cronotópicas enquanto procuravam identidades estáveis em lugares de onde eles não podiam escapar. A prática "pós-colonial" nega isso, posicionando seus referentes em um local mais móvel na superfície. Essa transformação performativa/deformativa também reflete a oposição que Michel de Certeau (1984, 93, 97) fez entre o pan-óptico "desejo de ser um ponto de vista" e a "opaca mobilidade [e] apropriação do sistema topográfico" pelo pedestre habitante-terrestre. Práticas de profundidade coloniais implicavam e se esforçavam para ser garantidas por uma superfície fotográfica que era invisível. A superfície era uma janela para um campo de correlações espaciais e temporais que codificaram uma "racionalidade" colonial. A opacidade da superfície se torna uma recusa dessa racionalidade e uma afirmação da singularidade cultural. Há também ressonâncias com a tentativa de Michel Taussig (1986) de reconfigurar "A obra de arte na era de sua reprodutibilidade técnica”, de Walter Benjamin, como aproveitável para o fim do século XX. Taussig está preocupado com a dimensão tátil e háptica do que Benjamin denominou de impulso "de se apossar" de objetos [fotografias] a curta distância (1968, 217; grifo do autor): o modernismo vernacular descrito no presente ensaio também revela um desejo de se apossar de objetos por meio da fotografia, e este tem uma contundênica particular em contextos pós-coloniais.

\section{FOTOGRAFIA E PROFUNDIDADE}

Aproveitando nossa presença na ilha, faremos um exame topográfico do lago sem pressa... deixe o leitor se esforçar para imaginar este adorável panorama espalhado em volta dele - todo objeto que é fielmente espelhado no calmo lago, cuja superfície no primeiro dia que o visitei era lisa como vidro - e ele então será capaz de formar alguma ideia do tipo de cenário que encanta cada visitante deste célebre vale. (Bourne 1866-67, 4)

2. Do inglês, “chronotopic”, o termo se refere a algo pertencente a um tempo ou lugar específico. (N.T.) 
Num aceno para o interior, através de uma divisória de madeira compensada e pisando cuidadosamente sobre uma trilha de cabos de luz elétrica, seguimos Suresh para dentro de seu estúdio. [Ele] depois, puxa a cortina vermelha revelando a pièce de résistance nesta câmara dos sonhos. A grande vastidão do Lago Dal na Caxemira é aberta, cintilando debaixo de montanhas cravejadas de pinheiros e cascatas, iluminado por céus eflorescentes, e tudo equilibrado por um primeiro plano deleitando-se em flores do campo multicoloridas. (Pinney 1997, 14-15)

Numa cena do popular filme hindu Beta, o apaixonado Anil Kapoor acaricia a fotografia de Madhuri Dixit, o ainda não correspondido objeto de sua afeição. A mão de Kapoor passa pela superfície da imagem, detectando alguma ondulação libidinal secreta, alguma textura do desejo dificilmente visível que desencadeia no sujeito da foto um sopro de êxtase. Olhar se torna tocar, e o referente da fotografia se transforma, do aprisionamento da profundeza da imagem para sua superfície sensorial. o cinema de Bombaim desenvolve aqui uma erótica do olhar e do ser, algo próximo à erótica descrita por Susan Sontag (1979)- uma urgência sensorial.

Retornarei ao "superficismo"3 que caracteriza uma prática fotográfica muito popular de pequenas cidades indianas quando, mais tarde, eu explorar suas continuidades com práticas populares da África Ocidental, especialmente as maneiras pelas quais o uso de panos de fundo, a criação da mise-en-scène fotográfica, e a manipulação pós-exposição da imagem demonstram uma preocupação com a superfície - ou o que olu Oguibe (1996) chama de "substância" da imagem - em vez de suas profundidades indexicais narrativizadas.

Meu argumento sobre práticas populares de "superficismo" pós-colonial depende, no entanto, de sua oposição a uma prática anterior que repudia e ultrapassa. Essa prática anterior privilegia o tempo/espaço da exposição fotográfica e conecta esses momentos de criação aos movimentos do fotógrafo e dos sujeitos fotográficos pelo tempo e espaço. A relação entre o início da fotografia e as viagens europeias não é acidental: a fotografia "normativa" codificou uma prática fotográfica, que por sua vez codificou uma prática de viagem. A ideologia de indexicalidade autorizou uma prática autóptica de "estar lá". Uma passada por qualquer história básica da fotografia revela a poderosa preocupação com a locação variável dos fotógrafos e seus equipamentos em conjunções reais de tempo/espaço, como os primeiros técnicos fotográficos em balões; John McCosh, em Burma; Roger Fenton, na Rússia e na Crimeia; Francis Frith, no Egito;

3. No original "Superficism" (N.T) 
Felice Beato, no Japão; Samuel Bourne, na Índia (ver Hershkowitz 1980); e Timothy O'Sullivan e W. H. Jackson, no Oeste Americano.

Há uma inovação na prática fotográfica que permite esse engajamento com espaços de alteridade, mas também permite uma ressonância com epistemologias mais duradouras. 0 paralelismo entre a tecnologia da fotografia e as técnicas de viagem tem sido explorado por David Tomas (1982; 1988), que observou o caminho no qual a transformação do negativo em um positivo encapsula uma jornada entre diferentes estados. Mas essa narrativa tecnológica estava baseada em uma tradição europeia de conceituar o conhecimento espacialmente muito mais antiga. 0 frontispício de Der Adeliche Hofmeister, de 1693 de Anton Wilhelm Schwart mostrando "o Grand Tour 4 como parte do sistema educacional Barroco" visualiza essa espacialização na qual diferentes disciplinas do conhecimento - incluindo "História Universal, Línguas Exóticas, Geografia e Política" - são retratadas como etapas ao longo de uma ambiciosa "peregrinação". Justin Stagl $(1990,325)$ situou tais imagens no contexto da ascensão de uma teoria sistemática de viagem na Europa dos séculos XVI e XVII.

Na origem da fotografia de viagem, como praticada por Fenton, Bourne e outros e cujo trabalho muito procurado veio a definir uma prática fotográfica canônica do século XIX, podemos traçar a aliança entre possibilidades tecnológicas da fotografia com uma expectativa cronotópica que emerge dessa longa história da teorização da viagem e do surgimento do autopticismo 5 , com a fórmula "ver com os próprios olhos".

De 1866, a Narrative of a photographic trip to Kashmir (Cashmere) and adjacent districts de Samuel Bourne servirá para os propósitos de nosso argumento como texto paradigmático dessa prática normativa. Ele começa sugerindo que "se estiver certo em supor que os leitores do The Brittish Journal of Photography se interessam por narrativas de viagem fotográficas em terras estrangeiras, eu dificilmente poderia esperar interessá-los mais fortemente, do que talvez apresentando-lhes algumas notas de uma viagem com uma câmera ao muito célebre Vale da Caxemira. " (Bourne 1866, 471)

o peso e o número dos apetrechos fotográficos de Bourne necessitam da formação de uma expedição de larga escala com quarenta e dois carregadores mais seu próprio séquito de servos, e a evidência da mentalidade isolante e conquistadora de mundo que esse tipo de formação expedicionária militarizada engendra é imediatamente evidente na narrativa

\footnotetext{
4. The Grand Tour se refere a tradicional viagem pela Europa realizada principalmente por homens jovens oriundos de classes altas e providos de meios, ou jovens de origem mais humilde quando conseguiam encontrar um patrocinador. (N.T.)

5. Do inglês, "autoptic", o termo se refere a algo relacionado ou pertencente à observação pessoal. (N.T.)
} 
de Bourne, que - como tem sido frequentemente observado - é recheada com uma aversão aos espaços dialógicos dos encontros cara a cara ("escutando o tempo todo nada além de bárbaros Hindustani") justapostos com momentos epifânicos de ascendência ("Todo o rico Vale de Kangra, que tem cerca de quarenta milhas de comprimento por quinze de largura, estava espalhado abaixo, cercado no lado oposto por uma soberba cadeia de montanhas"). 0 modo expedicionário e sua hostilidade ao encontro dialógico foi bem discutido por Gerd Spittler (1996), que o contrasta com a vulnerabilidade produtiva do viajante individual.

A dominação tem um apelo para Bourne, pois facilita uma visão abrangente ("Aqui e ali eu podia ver profundamente glens ${ }^{6}$ obscuros e aparentemente inacessíveis"). A sistematicidade da penetração imperial também era importante para Bourne ("Dificilmente existirá agora um recanto ou canto, um glen, um vale, ou montanha, muito menos um país, na face do globo em que o penetrante olho da câmera não tenha examinado" [apud Ryan 1997, 47]) e suas imagens fotográficas são oferecidas como casos exemplares dessas zonas antigamente inacessíveis, agora tornadas visíveis. $\mathrm{O}$ bem-sucedido resultado de viagem é avaliado nesses momentos de altura e distância, ao passo que a proximidade marca um fracasso ("Percebi que não seria capaz de ter uma visão geral do todo por conta da proximidade da parede que o cercava" [Bourne,1866-67, 475]). Todas essas emoções conflitantes e experiências são resolvidas no momento de epifania de sua subida além do Vale da Caxemira:

O topo era formado por um cume de linha reta ou parede de neve de cerca de oito pés de largura, onde eu sentei para descansar e examinar o cenário que se fez ao meu redor... o panorama não era só o mais extenso, mas o mais variado que já avistei.

Aqui eu tive o meu primeiro vislumbre do "Vale da Caxemira", que se estendia ao norte como uma planície nivelada, com uma mancha brilhante aqui e ali reluzindo através da névoa, como prata, os reflexos dos lençóis de água... À direita, outras pirâmides de neve surgiram à vista numa sucessão gloriosa e ilimitada, se estendendo, eu presumo, ao território de Ladakh. olhando para o sul (de onde eu tinha vindo) uma sucessão de vales e cumes seguidos uns aos outros, por muitas léguas, cordilheira além de cordilheira, até se perderem nos cumes mais altos e na neve gigantesca de Pangi, que, por sua vez, se mistura com a sombria escuridão das nuvens que pairam.

Que espetáculo foi olhar para isso tudo! (Bourne 1866-67, 584)

6. Um glen é um vale tipicamente estreito, longo, profundo. (N.T.) 
O sentimento de Bourne aqui ecoa as diferentes respostas de Gustave Flaubert para os variados espaços do Cairo durante sua viagem em 1850 com o fotógrafo Maxine Du Camp:

O que posso dizer disto tudo? O que posso te escrever? Até agora mal superei o deslumbramento inicial... Cada detalhe estende a mão para te agarrar, te beliscar; e quanto mais você se concentra, menos você compreende o todo. Então, gradualmente, tudo isso se torna harmonioso e as peças encaixam-se, de acordo com as leis da perspectiva. Mas os primeiros dias, por Deus, é um caos desconcertante de cores. (Flaubert apud Mitchell 1988, 21)

Como Timothy Mitchell (que cita Flaubert em sua grande obra Colonising Egypt) sugere, Flaubert contrasta uma experiência ameaçadora de proximidade (na qual a visão se colapsa em toque: "te belisca") com a segurança da distância e da altura, que permite uma observação separada de uma totalidade ("de acordo com as leis da perspectiva"). Mais tarde, Marcel Griaule - que tem uma conhecida inclinação à fotografia aérea - comentou: "Talvez seja uma peculiaridade adquirida em aviões militares, mas sempre fico ressentido em ter que explorar terreno desconhecido a pé. Visto do alto, no ar, um distrito contém alguns segredos" (Griaule apud Clifford 1988, 68). A temática de um conhecimento colonial superior proporcionado por aeronaves poderia ser o assunto de um pequeno livro, cujo texto-chave seria "The importance of Java seen from the air" de H. M. de Vries (1928), que inclui uma recomendação do presidente da associação local de aviação Batavia:

Agora nós, filhos do século, estamos sem delongas flutuando pelo ar em nossos aviões ou balões, impulsionados por máquinas, ao passo que habilitados além disso pela perfeição das lentes fotográficas, estamos numa posição de fixar nas placas sensíveis o que, das alturas vertiginosas, nos chamou atenção, e depois, com a ajuda da arte gráfica, demonstrar como o mundo embaixo se apresenta ao olho que espia das nuvens.

Uma das fotografias, "A road lined with poplars", que resultou da excursão de Bourne à Caxemira, diagrama perfeitamente a varredura diagonal de uma linha retrocedente de árvores dividindo o plano da fotografia em fragmentos geométricos. Embora para Rosalind Krauss, seguindo Peter Galassi (1981, 93), a imagem de Bourne "esvazia a perspectiva de seu significante espacial e reinveste cada pedaço com uma ordem bidimensional de forma tão poderosa tal como um Monet contemporâneo" (Krauss 1985, 135), esse achatamento e a característica gráfica da imagem de Bourne 
ocorre com certeza em função de má reprodução da imagem nas fontes disponíveis a Krauss (provavelmente também a Galassi) e seu afastamento dela provocado pela narrativa de Bourne que insere sua linha pictórica de voo na câmera penetrante imperialista do norte da Índia.

A narrativa e as imagens de Bourne mapeiam um espaço no qual o mundo é, como para Heidegger, uma imagem. No seu fundamental e desconcertante ensaio The age of the world picture (1977), Heidegger explorou a maneira pela qual uma modernidade europeia havia produzido uma profunda clivagem entre homem e o mundo. 0 mundo se tornou um campo de certezas espaço-temporais, um domínio entregue a medir e executar o que mais tarde Merleau-Ponty descreveu como "espacialidade isotrópica homogênea". Para a caracterização de Heidegger desse tropo também podemos adicionar o elemento crucial da narrativa: o mundo como imagem implicou também caminhos interrogativos, incursões nas quais vidas se tornam medidas em termos de suas "explorações", e a exploração do mundo como uma imagem se torna a marca de vidas vividas com sucesso.

A fotografia pós-colonial africana e indiana contemporânea está preocupada com um domínio do "desnarrativizado", efeitos de superfície "desperspectivados" que operam em uma zona de tatilidade muito diferente do ponto de vista desconectado defendido pelos primeiros praticantes europeus, como Bourne. No entanto, não estou sugerindo que essa recusa da narrativa, perspectiva e distanciamento seja peculiar da fotografia. Pelo contrário, como mostrarei através de diversos exemplos, essa é uma recusa feita em outras mídias também. De fato, é também uma recusa, presente em "momentos de inquietude" dentro de esquemas de pinturas dominantes como a "arte de descrever" do norte, discutida por Svetlana Alpers, e a "loucura da visão" presente no barroco.

Tal argumento tem sido construído por Martin Jay (1988) em sua consideração sobre os múltiplos regimes escópicos que têm constituído a modernidade. Jay argumenta que a história de dominância de um único regime escópico- que ele chama de "perspectivismo cartesiano" - é muito simples. O termo "perspectivismo cartesiano" funde a racionalidade subjetiva cartesiana com conceitualizações albertianas de perspectivas de ponto único. É central para essa noção a visão desincorporada - o que Norman Bryson $(1983,95)$ chama de "visão desencarnada" - e que analisei em outros trabalhos (seguindo Susan Buck-Morss) como uma "anestética" em oposição a uma "corpotética". Dentro da perspectiva cartesiana, Bryson $(1983,94)$ sugere que

7. Pinney 2001. Por anestética, segundo Buck-Morss, quer dizer o domínio da estética descorporificada anti-kantiana. o neologismo "corpotético" destina-se a evocar o domínio da estética sensível e corporal. 
o corpo é reduzido a... sua anatomia ótica, o diagrama mínimo da perspectiva monocular. Na Percepção Fundadora, o olhar do pintor detém o fluxo de fenômenos, contempla o campo visual de um ponto vantajoso fora da mobilidade da duração, em um momento eterno de presença revelada.

Jay $(1988,8)$ esboça uma variedade de consequências decorrentes da ascensão dessa nova ordem visual. A lacuna entre o observador e o que foi representado na imagem se alargou, e ocorreu uma "deserotização" da ordem visual conforme o mundo retratado em imagens era cada vez mais "situado em uma ordem espaço-temporal matematicamente regular preenchidas com objetos naturais que só poderiam ser observados de fora" (Ibid. 9).

0 ensaio The age of the world picture de Heidegger foi produzido em 1935 - um ano antes do ensaio de Benjamin sobre a "Obra de Arte" - e há certos paralelos intrigantes entre os dois argumentos. Ambos ensaios desenvolvem extraordinariamente narrativas evolucionárias amplas e ambiciosas. Na história otimista de Benjamin, o declínio de uma aura situada anteriormente é previsto por novas tecnologias da imagem. $\mathrm{Na}$ história pessimista de Heidegger, uma positiva valorização do habitar pré-moderno é rompida pela perspectiva cartesiana onde o mundo passa a ser visto como uma imagem - uma zona de representação estabelecida como algo exterior à existência. Retratar se torna inseparável da modernidade: "O fato de que o mundo se torna uma imagem em absoluto é o que distingue a idade moderna" (Heidegger 1977, 130).

Se para Parmenides, "o homem é aquele que é encarado pelo que é" na idade moderna, "aquilo que é... passa a existir... através do fato de que primeiro o homem olha para ele" (Ibid. 130, 131). Olhar o mundo e construí-lo como uma imagem acarreta a colocação do homem, por ele mesmo, contra e antes da natureza como algo separado: o mundo é "colocado no domínio do conhecimento do homem e a sua disposição" (130). ${ }^{8}$

Jay se opõe à hipótese considerada por comentadores tão diversos quanto Richard Rorty e William Ivins Jr. de que o perspectivismo cartesiano tem sido o único regime dominante desde o Renascimento. Ele chama a atenção para outros paradigmas bastante diferentes que por vezes destronaram a suposta hegemonia do regime da perspectiva cartesiana. Assim, a "arte de descrever", que floresceu nos países baixos durante o século XVII, rejeitou a narrativa e perspectiva anterior da pintura do

8. Para uma apresentação prolongada destas ideias para as práticas europeias de viagem, ver Pinney (1994). 
Renascimento do sul europeu em favor de uma textura visual desnarrativizada. Em vez de um ponto de olhar fixo, demandava um olhar móvel, itinerante, que escaneasse os detalhes dispersos nas imagens que frequentemente incluem palavras em adição a objetos em seus espaços visuais (Jay 1988, 12). Entre os contrastes que Alpers traça entre essa arte de descrever e as imagens perspectivistas de antes estão a "luz refletida de objetos contra objetos modelados pela luz e pela sombra; a superfície dos objetos, suas cores e texturas tratadas ao invés de sua colocação em um espaço legível" (Ibid. 1988, 12-13).

o segundo momento de inquietação descrito por Jay sustentava a possibilidade de uma recusa mais radical do perspectivismo. 0 barroco (um termo provavelmente derivado da palavra portuguesa para uma pérola disforme) é adiantado por Jay como "uma permanente, e com frequência reprimida, possibilidade visual existente ao longo da era moderna" (Ibid. 16). Utilizando-se do trabalho de Christine Buci-Glucksmann, Jay enfatiza a rejeição pelo barroco da "geometrização monocular da tradição cartesiana, com a sua ilusão de espaços tridimensionais homogêneos vistos de longe por meio de um Olhar de Deus". o barroco é obcecado pela opacidade, pela recursividade da superfície e pela profundidade e "revela o convencional ao invés da qualidade natural da especulação 'normal' por mostrar sua independência da materialidade do meio de reflexão" (Ibid. 17). Em outros trabalhos (Pinney 1999), examinei a cultura visual popular indiana em termos barrocos como evocado por Alejo Carpentier, que em uma palestra, em 1975, esboçou uma teoria da relação do barroco com o realismo mágico que possui uma peculiar aplicabilidade às imagens que considerarei brevemente aqui.

Apesar do barroco ser, para Carpentier (1995, 93), uma "constante do espírito humano", também precisa ser compreendido como uma reação a uma racionalidade espacial. o barroco "é caracterizado por um horror ao vácuo, a superfície nua, a harmonia da geometria linear" (loc. cit.); "foge dos arranjos geométricos" (Ibid. 94). Carpentier vê a Catedral de São Pedro em Roma, de Bernini, como um exemplar do barroco; é como um sol enjaulado, "um sol que expande e explora as colunas que o circunscreve, que aparenta demarcar seus limites e literalmente desaparece antes de sua suntuosidade" (Ibid. 93). Podemos adicionar à ênfase de Carpentier na natureza crioula e híbrida do realismo mágico a observação de Luis Leal (1995, 121), de que o realismo mágico é uma "atitude em relação à realidade" e não só um gênero literário", bem como a reivindicação de Amaryll Chanady $(1995,135)$, de que o realismo mágico "adquire uma

9. Leal $(1995,121)$ argumenta que o realismo mágico "não cria mundos imaginários nos quais podemos nos esconder da realidade cotidiana: no realismo mágico o autor confronta a realidade e tenta desembaraçá-la, para descobrir o que é misterioso nas coisas, na vida, nos atos humanos". 
significância particular no contexto do status Latino Americano de uma sociedade colonizada", e sua observação de que o realismo mágico é uma resposta a "regras, normas e tirania da idade da razão".

Essa preocupação com perspectivas teóricas que se desenvolve a partir da consideração da pintura e da literatura pode parecer desconcertante dado que meu interesse é a fotografia. o que tentei demonstrar, no entanto, é que o "barroco" - o apelo à superfície háptica - é comumente evocado através de diferentes mídias. o que todas essas estratégias de superfície têm em comum é sua emergência em contextos pós-coloniais específicos como expressões de identidade que, de maneiras complexas, repudiam os projetos dos quais imagens de um perspectivismo cartesiano fazem parte.

Entretanto, a distância entre essas ideias abstratas e as práticas fotográficas indiana e africana populares é pequena. Judith Mara Gutman (1982, 17) escreveu sobre uma das fotografias de Samuel Bourne do sul da Índia (View into Ootacummund) em termos que espelham de perto a descrição de Dawn Ades das paisagens italianas de Claude:

um baixo nível de luz é introduzido em primeiro plano, e em seguida se permite seu movimento dentro e fora das árvores, criando graciosas curvas líricas por entre as folhas. A luz se projeta a alturas majestosas, com dramáticas fendas de sombra, antes de desaparecer na distância. Bourne teceu uma história em sua imagem, guiando os seus espectadores desde o primeiro plano de ritmo mais lento e desconexo pela intensidade edificada do plano médio, e depois discretamente levando seus espectadores para um futuro distante.

Essa imagem, que é tão cuidadosamente construída - de modo a permitir que o olho do espectador viaje pelo seu espaço interno -, pode ser contrastada com outra fotografia examinada por Gutman, "Women at Sipi Fair" (1905). Essa imagem, de um fotógrafo indiano desconhecido, está sujeita a um regime espacial muito diferente: "Sem 'convite' para dentro da imagem, meus olhos não sabiam como ou onde entrar... Não havia caminhos, como os encontrados no imaginário Ocidental, para as outras partes da imagem" (Gutman 1982, 6).

\section{O PANO DE FUNDO REALISTA}

Escrevendo sobre a fotografia da Guerra Civil Americana, Alan Trachtenberg $(1985,1)$ observou o que ele chama de "historicismo pela fotografia”, noção na qual- no despertar da consagração da fotografia pela guerra - o "conhecimento histórico declara o seu verdadeiro valor através do quanto e como é fotografado". Talvez a afirmação mais clara dessa 
transformação na natureza de eventos históricos repousa na conclusão de Paul Valery, 100 anos depois da introdução da fotografia, de que "a mera noção de fotografia, quando introduzida em nossa meditação na gênese do conhecimento histórico e seu verdadeiro valor, sugere a simples questão: Poderiam tal e tal fato, como é narrado, ter sido fotografado?" (Valéry apud Trachtenberg 1985, xiii-xiv).

A observação de Valéry expressa uma visão padrão da fotografia como índice - como um traço químico da luz que, ricocheteada de objetos, que passam diante das lentes - e possuidora de um elemento de aleatoriedade que sempre elude o desejo do fotógrafo de enquadrar e construir a imagem. É a incompletude do filtro fotográfico que a distingue de outras mídias, tais como a pintura e o desenho. Implicitamente nessa visão há um desejo de aprisionamento dentro do tempo-espaço do mundo cotidiano, capturado pela câmera.

A fotografia pode ser usada para posicionar corpos e rostos dentro da história, e pode também ser usada como um meio de fuga. o que Eduardo Cadava (1997, xxix) descreve como "autoarquivamento fotográfico" posiciona corpos dentro de cronotopias específicas - é importante para algumas pessoas que a imagem da Torre Eiffel, a distância, seja aquela do centro de Paris e não um simulacro: como Bourdieu diz, "consagra o encontro único" (1990, 336). A cronotopia indiana central que será agora brevemente descrita não privilegia esses fatores porque sua linguagem fotográfica lúdica não está preocupada em fixar corpos em tempos e lugares particulares; em vez disso, ela está preocupada com o corpo como uma superfície que é completamente mutável e móvel, capaz de se situar em qualquer tempo e espaço.

Se temos que em algumas tradições fotográficas panos de fundo são valorizados como um registro da posição do sujeito em um lugar real particular (geralmente, como Bourdieu nota, em encontros com lugares de produção altamente simbólica), pouquíssimas pessoas em Nagda (uma cidade com 79.000 pessoas na Índia Central, a meio caminho entre Deli e Bombaim) pedem para ser fotografadas no espaço real de Nagda. Isso geralmente ocorre somente no processo de fotografar procissões de casamento, conforme eles passam pelas ruas da cidade ou pelos jardins do Birla mandir local, um elaborado templo pseudoarcaico cujo terreno se tornou um lugar popular para piqueniques para os habitantes mais ricos da cidade. As fotografias tiradas aqui (majoritariamente por fotógrafos profissionais que espreitam os jardins) tratam com desprezo a especificidade topográfica do lugar em favor de panos de fundo estereotipados (do tipo a ser visto em filmes Hindus) de flores e fontes. 


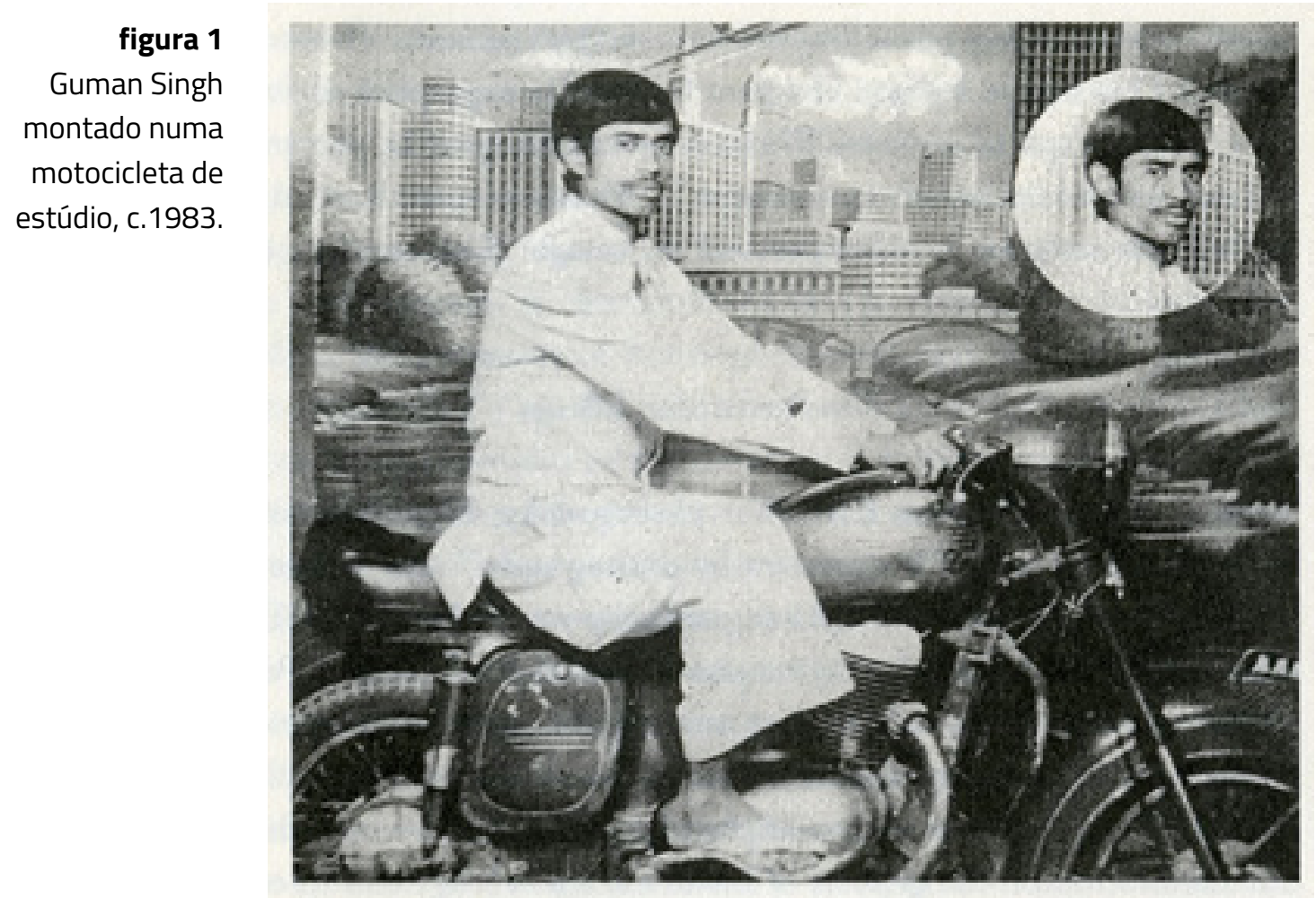

Quando os Nagdarites querem uma foto de si mesmos eles quase sempre incumbem um fotógrafo (pois há muitas poucas câmeras de propriedade privada) para fotografá-los dentro de um estúdio. o lugar "real" de Nagda é continuamente rejeitado em favor daquilo dentro das dependências do fotógrafo (Figura 1). Um pano de fundo será escolhido talvez o Taj Mahal, ou uma cena no lago Dal (Caxemira), ou ainda uma paisagem urbana (vista de uma motocicleta). o mesmo deslocamento espacial/temporal pode ser atingido através do "cutting" - a cuidadosa justaposição de negativos em papel e impressão composta que permite noivas e noivos em álbuns de casamento viajarem por toda a extensão da Índia, estando em um momento de pé ao lado da Torre da Vitória em Chittorgarh e em outro ao lado do Portão da Índia em Deli.

\section{O PANO DE FUNDO"SUBALTERNO"}

Em Afterimage, o antropólogo Arjun Appadurai (1997) sugeriu que a disseminação do uso de adereços e panos de fundo na fotografia popular pós-colonial expressa uma resistência à reivindicação documental da fotografia e traz à tona críticas à modernidade. Ele chega ao ponto de nomear o pano de fundo de "subalterno": 


\begin{abstract}
o pano de fundo resiste, subverte ou parodia a reivindicação realista da fotografia de várias formas... Nessas configurações pós-coloniais, panos de fundo fotográficos se tornam menos local de debates sobre a subjetividade colonial do que para... "experimentos com a modernidade". Isto é, fora das técnicas taxonômicas e coercitivas dos observadores coloniais e do estado colonial, os panos de fundo tendem a se tornar parte de um diálogo mais complicado entre fotos posadas e práticas cotidianas. (Ibid. 5)
\end{abstract}

Em Nagda, panos de fundo não são usados simplesmente como substitutos na falta de seus referentes, mas como um espaço de exploração. Essa exploração é comumente geográfica: dentro dos estúdios de Nagda pode-se viajar de Goa a Mandu, a Agra e a Caxemira meramente ao ficar de pé em frente a diferentes paredes. Mas os estúdios de Nagda também funcionam como uma câmara dos sonhos em que explorações pessoais de uma gama infinita de alter egos é possível.

Retratos duplos e triplos colocam uma pessoa além do espaço e identidade que certas formas do retrato Ocidental possuem. Estas, junto com as complicadas técnicas de montagem que são tão comuns nos retratos de Nagda, testemunham a falta de desejo de "capturar" os fotografados dentro de quadros espaciais e temporais limitados. A replicação de corpos e rostos trazidos por dobrar e triplicar imagens rompe não só os correlatos espaciais e temporais que são operados pela janela perspectivista criada pela fotografia, mas também sugere uma diferente conceitualização dos objetos que foram fabricados para aparecer nessa janela. É como se existisse uma homologia entre as infrações espaciais e temporais dessa janela representacional e a fratura desses sujeitos locais.

Mas não são apenas panos de fundo que sugerem esse paralelismo africano/indiano. Há também um reconhecimento explicitamente articulado por fotógrafos de que sua tarefa é produzir não um vestígio aprisionado de seus fotografados, mas atuar como grandes empresários, trazendo à tona uma visão ideal e aspiracional dos corpos que os fotografados anseiam ser.

\title{
"SAINDO MELHOR..."
}

Ninguém em Nagda - além, isto é, da polícia e de outros agentes do estado - vê algum valor no potencial da fotografia de fixar a realidade quotidiana. Ela é raramente usada para registrar ou memorizar eventos e conjunturas do passado. A fotografia, por outro lado é valorizada, por sua habilidade de fazer pessoas e lugares "saírem melhores do 
que realmente são"10. Essa é uma frase usada por clientes do estúdio Sagar em Nagda, que é famoso por suas revelações de cor em dobro. o proprietário, Vijay Vyas, comenta que os Nagdarites raramente desejam fotografias "realistas" (vastavik): "Eles sempre dizem eu quero sair bem... Todo mundo diz eu sou assim, mas quero sair melhor que isso na minha foto (is se bhi zyada acchha mera photo ana chahie). Então tentamos"

"Sair melhor" em uma fotografia em Nagda é possível por meio de dois caminhos: a adoção de gestos e a disposição de figurino e adereços. Frequentemente um implica o outro. Vijay Vyas se refere a qualquer foto envolvendo um gesto com a frase em inglês "action shooting": "action shooting ou foto-ação significa que você está com a mão de certo modo, para o alto, para mostrar o seu relógio; uma perna mais para cima que a outra. Essas são as foto-ação". Isso se refere a um conjunto de técnicas combinadas entre o fotografado e o fotógrafo que permitem uma pose específica emergir e que pode envolver conjuntamente um gesto ou um olhar pelo sujeito e a adoção de um ângulo apropriado da câmera pelo fotógrafo. Assim, há poses de "poeta" de "filmi" (isto é, estrela de cinema), ambas requerem ângulos de câmera baixos, e a criação delas envolve uma espécie de direção teatral do fotógrafo (Figura 2).

Vijay, como muitos outros donos de estúdios em Nagda, tem uma coleção de figurinos disponíveis para o uso de seus clientes, embora eles sejam a causa de considerável confusão. Os figurinos incluem uma roupa tipo " tudo em uma", que pode ser arranjada para diferentes gostos regionais, de casta e classe. Perguntei a Vijay por que seus clientes são tão interessados em roupas diferentes quando estão em frente à câmera:

Por shauq [prazer, para satisfazer um desejo]. Eles não querem usar suas roupas do dia a dia. Eles não querem fotos vastavik [realistas]... Eles penteiam e trançam o cabelo, passam talco, passam creme, colocam um batom, mudam suas roupas, vestem roupas boas, colocam uma gravata, vestem um casaco, se certificam de que suas calças estão ok, e então eles dizem 'tire uma foto-ação', 'tire minha foto com este tipo de vestido, vestido Rajasthani, com um matka [pote de barro] e assim por diante. (Vyas, informação verbal)

10. Os três parágrafos seguintes são condensados de Pinney (1997a, 178-80); o material citado é de entrevistas com o autor, traduzidas do Hindi. 
figura 2

Composição de Suhag Studios, Nagda, c. 1980.

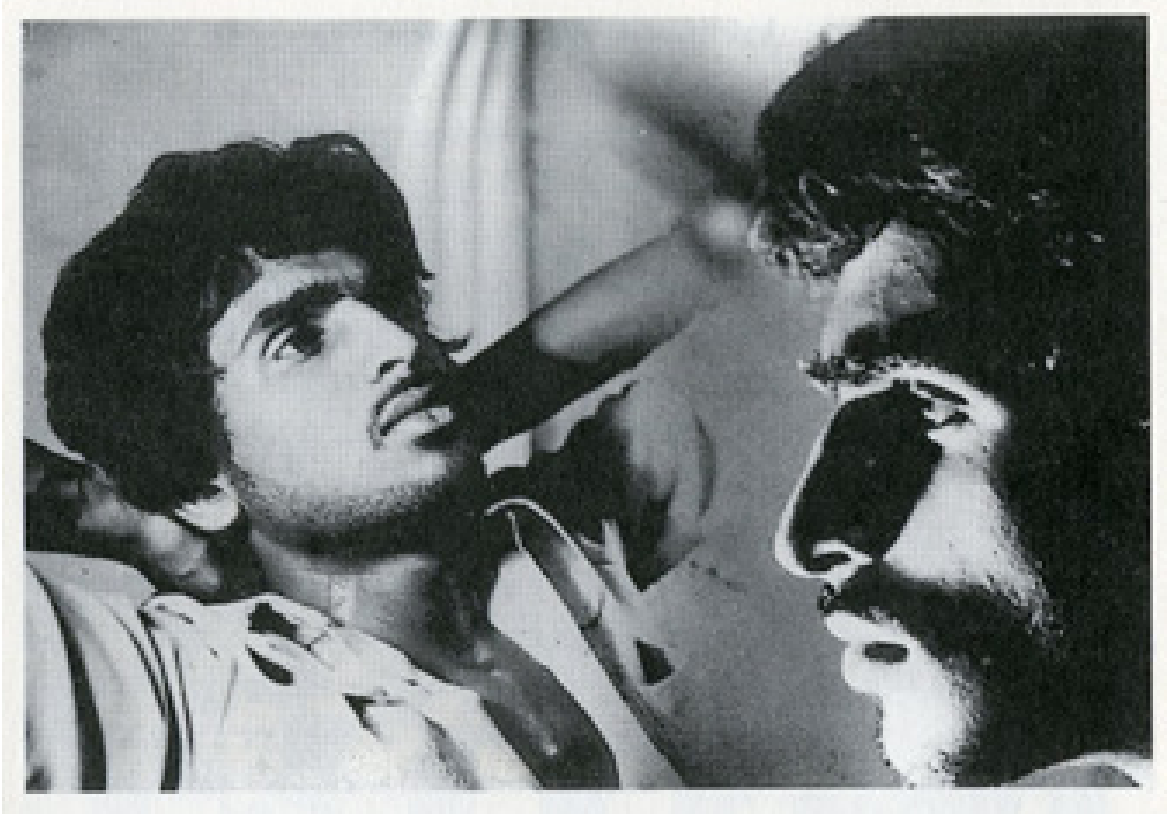

Considerando que a fotografia popular de Nagda não parece compartilhar muito da função solenizante da fotografia francesa descrita por Pierre Bourdieu (1990, 24), existem perspectivas que podem ser tiradas de algumas práticas na África Ocidental. Kobena Mercer (1995, n.p.) descreve a abordagem do fotógrafo Seydou Keïta, ativo em Bamako, Mali, desde meados dos anos 1940, como segue

Com vários apetrechos, acessórios e panos de fundo, o fotógrafo estiliza o espaço pictórico, e através de iluminação, profundidade de campo e enquadramento, o trabalho da câmera intensifica a mise-en-scène do sujeito, cujas poses, gestos e expressões revelam desse modo um "eu" não como ele ou ela é realmente, mas "só um pouco mais do que nós realmente somos".

o comentário no final é do próprio Seydou Keïta, e inquietantemente reflete a observação feita por Vijay Vyas.

\section{MODERNISMO VERNACULAR}

Vindo de uma imersão nas práticas populares de fotografias indianas, somos golpeados imediatamente com as similaridades apresentadas por estudos da fotografia popular africana: parece existir um desinteresse 
similar em cronotopias realistas, uma recusa similar do perspectivismo cartesiano, até mesmo na forma atenuada de suas populares encarnações euro-americanas contemporâneas. Algumas das aparentes continuidades podem ser em parte explicadas por uma continuidade de pessoal: os estúdios pesquisados por Heike Behrend (1998) em Mombaça são em grande medida dirigidos por indianos, e a poderosa influência do cinema de Bombaim por toda a África Ocidental (Larkin, 1997) e o impacto da iconografia indiana produzida em devoção a Mami Wara sugere possíveis linhagens de influência.

O trabalho de Seydou Keïta (defendido pelo mundo da arte como fotógrafo africano fundamental poderia ser assunto de outro ensaio) é particularmente ressonante com o retrato indiano popular. Os clientes de Seydou Keïta possuíam, no entanto, uma escolha muito mais restrita de panos de fundo. Como Seydou relatou ao The Guardian em 19 de abril de 1997, "Entre 1949 e 1952, usei minha colcha de franjas como meu primeiro pano de fundo. Depois eu mudava o pano de fundo a cada dois ou três anos". Em outra fonte ele acrescenta que isso introduzia um elemento de indeterminação: "Às vezes o pano de fundo funcionava com a roupa deles, especialmente para as mulheres, mas era tudo por acaso" (Keïta apud Bigham 1999, 58).

Esses panos de fundo trocados esporadicamente contribuem significativamente para o visual de Seydou - e para sua recusa da cronotopia realista. Qualquer locação fora do espaço imaginário do estúdio é continuamente ultrapassada pela textura das várias colchas de Seydou entrando em harmoniosa e dissonante conversa com as roupas e acessórios vestidos por seus fotografados (Figura 3). Essa conjuntura produz uma "arte de descrever" malinesa, uma fotografia de superfície que envolve a textura, em que tudo salta da fotografia em direção ao espectador, em vez de um campo de certeza espaço-temporal recuado dentro da imagem ${ }^{11}$. Isso é o que podemos rotular de "modernismo vernacular": uma recusa de verificação externa motivada não pela angústia greenbergiana, mas pelo desejo de consolidar o espaço íntimo entre o espectador e a imagem. As mais populares imagens de Seydou datam dos anos 1950, talvez porque os sujeitos irradiam o otimismo dos ventos de mudança de um futuro imaginado (Figura 4), em vez do cansaço da "banalidade" pós-colonial mbembesque (Mbembe, 1992). O material discutido por Stephen Sprague em seu maravilhoso artigo (1978) sobre a fotografia Iorubá data em grande parte dos anos 1970, e as ressonâncias com práticas indianas populares são ainda mais acentuadas: aqui há um mundo de superfícies e materialidades que estende a mão a seus espectadores encarnados.

11. Bigham $(1999,57)$ resume algumas dessas características pictóricas como centralidade e estabilidade composicional, com figuras fixas centralmente frequentemente mostradas frontalmente, inteiramente e dentro de um espaço pictórico superficial. 
figura 3

Sem título,

1956-57.

Cortesia Sean

Kelly Gallery,

New York.

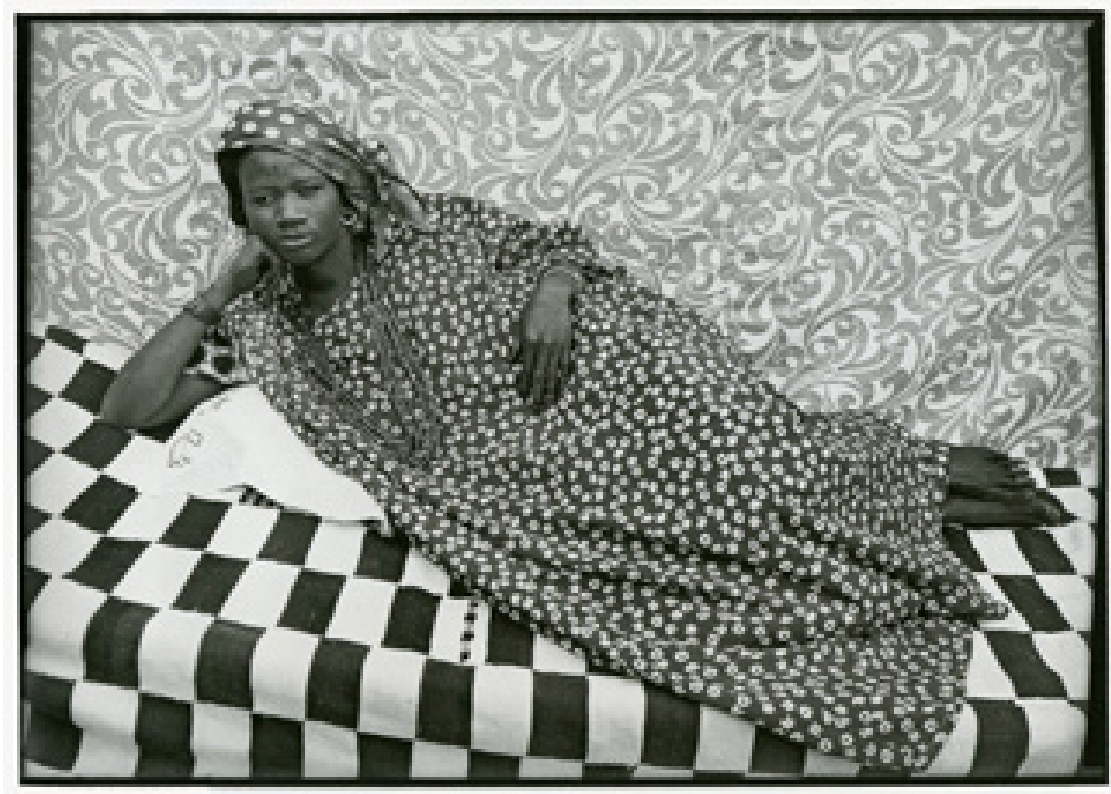

figura 4

Sem título, 1958.

Cortesia Sean

Kelly Gallery,

New York.

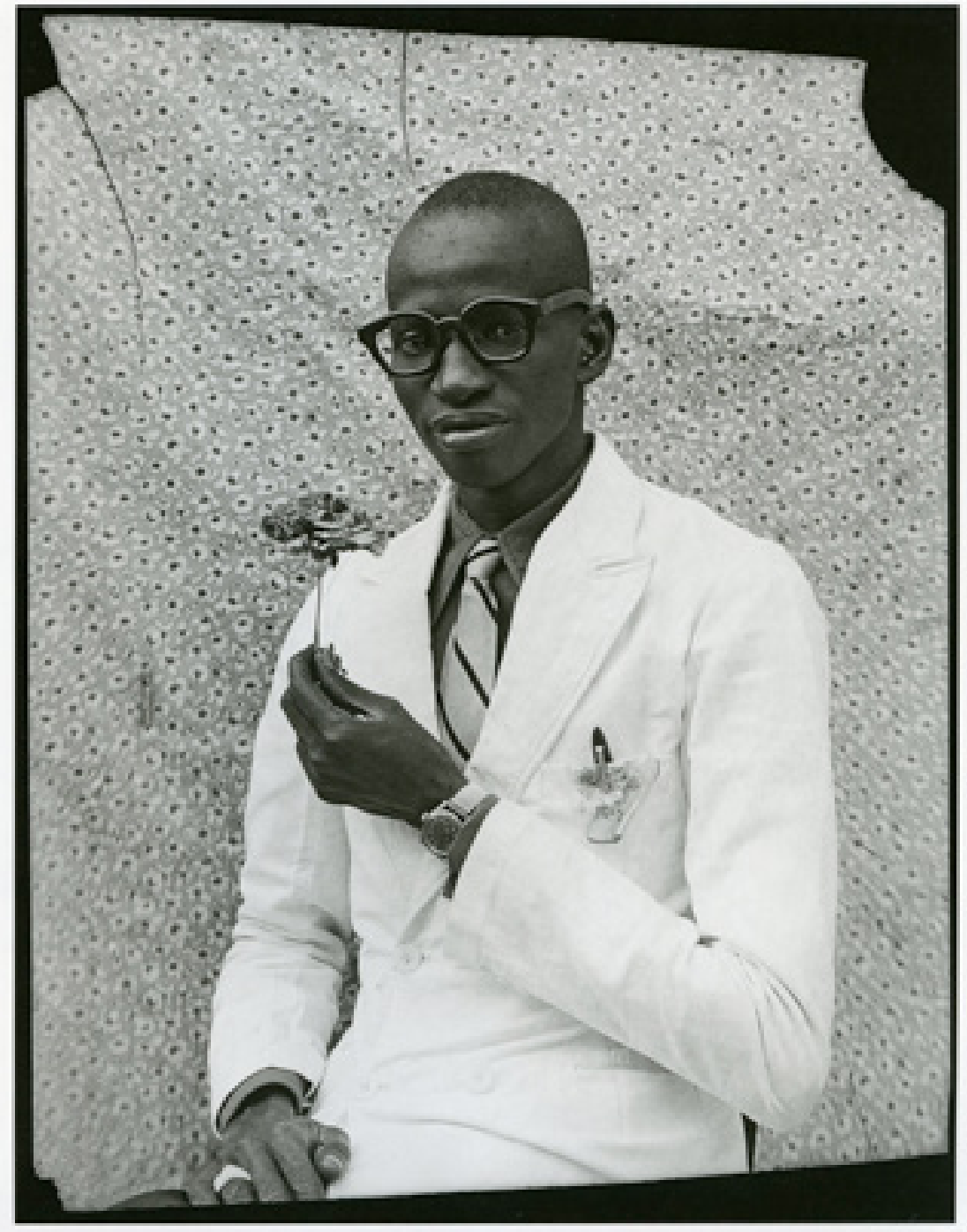


Como em Nagda, há uma desconfiança de imagens que não são recíprocas ao olhar do espectador: imagens de perfil e "obscuras" que não revelam completamente o rosto frustram o real propósito da fotografia para os Iorubás. Sprague descreve um número de poses e gêneros altamente convencionais, incluindo o "retrato fotográfico formal" tirado por um Iorubá mais velho. 0 sujeito aparece em sua melhor roupa tradicional "encarando diretamente a câmera" com as pernas afastadas e mãos nos joelhos ou colo e "os olhos olham diretamente para a câmera" (Ibid. 1978, 54). Significativamente, Sprague observa que, apesar das restrições técnicas dos primeiros processos fotográficos e a duradoura influência dos primeiros retratos britânicos serem frequentemente apresentados para explicar essas práticas Iorubás, não há, de fato, nenhuma relação óbvia entre as duas.

A preocupação com a superfície da imagem e sua produção depois do momento fotográfico ser evidente nas práticas Iorubás em diversas formas, têm paralelos indianos. Recortes fotográficos são comumente feitos com a colagem de imagens fotográficas (e em alguns casos imagens de revistas) em finas lâminas de madeira, às quais uma base de suporte é adicionada ${ }^{12}$. Impressões duplas e mais complexas, que rompem com o que Gombrich uma vez chamou de "princípio da testemunha ocular"13 é comumente usado, especialmente na representação de irmãos falecidos no culto de gêmeos ibeji. Alguns estúdios, como o Sir Special, em Ila-Orangun, montavam imagens fotográficas dentro de molduras espelhadas, cuidadosamente removendo as manchas de forma que o contorno do corpo fotografado poderia ser visto do outro lado (Spargue 1978, 59), uma técnica comum na exibição de cromolitografias na Índia Central. Estúdios Iorubás também produzem agrupamentos complexos que justapõem imagens fotográficas com inscrições textuais (Sprague reproduz uma com a frase "Ser [um] homem é um problema"), criações que pareceriam familiares aos produtores de Nagda.

Ambos superficismos populares, indiano e africano, são garantidos em todos os pontos pelo desejo de clareza e visibilidade, e em ambos locais os olhos do sujeito se tornam cruciais criadores da habilidade da imagem de devolver o olhar do espectador: os olhos se tornam o sustentáculo da relação entre a imagem e o mundo fora dela. Sprague $(1978,56)$ observa que uma das convenções fundamentais que governam a fotografia Iorubá é que "ambos os olhos do sujeito devem estar sempre visíveis em

12. Eu não encontrei isso em Nagda, mas um fotógrafo/artista, Bishumber Dutt de Mussoorie, no norte da Índia (cujo trabalho é descrito no filme Photo Wallahs de David e Judith MacDougall), ganha a vida da produção de tais recortes fotográficos em tamanho natural (Ver MacDougall 1992).

13. Isto é, que uma imagem retrata o que uma pessoa poderia realmente ver. 
um retrato. Essa convenção refere-se ao conceito de ifarahon - de visibilidade e clareza da forma, linha e identidade". Isso ressoa muito profundamente com as práticas em Nagda e com a mais abrangente noção de darshan, de ver e ser visto, que também informa a busca dos Nagdarites por frontalidade e visibilidade inscritas em uma superfície que olha para fora, de modo a devolver o olhar do espectador.

Mas, além disso, existe em grande parte da fotografia popular africana e indiana uma preocupação surpreendentemente semelhante com a materialidade da imagem e com as maneiras pelas quais a superfície da imagem se torna um lugar para a autoformação de identidades pós-coloniais. O que é notável sobre as práticas discutidas anteriormente são suas descontinuidades com a tradição histórica das quais elas emergem e suas continuidades com outras práticas pós-coloniais contemporâneas. Práticas populares indianas, africanas, haitianas (Houberg 1992) e chinesas ${ }^{14}$ estão ligadas por um interesse comum, não com o espaço a fotografia como uma janela em uma realidade marcada por linhas de fuga internalizadas, mas com a fotografia como uma superfície, um terreno, no qual presenças que olham em direção ao observador podem ser construídas. Como Olu Oguibe $(1996,246)$ elegantemente descreve essa transformação, "a imagem em questão não é a figura perante a câmera, mas aquela que emerge depois do momento fotográfico". Se o momento fotográfico é dedicado a capturar o mundo como uma imagem, o que emerge posteriormente é a materialidade da imagem: o que Oguibe chama de sua "substância" e o que aqui discuto em termos de superfície. Um espaço imagético superficial, técnicas de colagem e montagem, pintura sobre a foto e mediações esculturais complexas transpõem o foco das imagens fotográficas do espaço entre a janela da imagem e seus referentes para o espaço entre a superfície da imagem e seus espectadores. É essa "descolonização visual" (Appadurai 1997, 6) que tentei evocar nestas notas sobre a superfície da imagem.

\section{NOTAS}

Sou grato a Michael Godby por me convidar à Cidade do Cabo, em 1999, onde apresentei a primeira versão deste ensaio.

\footnotetext{
14. À luz de Sprague se poderia reler a narrativa da fotografia popular chinesa de Sontag $(1979,173)$ de modo a revelar sua natureza corpotética e superficista: "Nenhuma fotografia é espontânea, nem mesmo as do tipo que o usuário de câmera menos sofisticada nesta sociedade acha normal - um bebê engatinhando no chão, alguém gesticulando... geralmente o que as pessoas fazem com a câmera é se reunir para ela, em uma fileira ou duas. Não há interesse em capturar movimento".
} 


\section{REFERÊNCIAS BIBLIOGRÁFICAS}

Appadurai, Arjun. 1997. "The Colonial backdrop". Afterimage 24 (5) (March/April): 4-7.

Baker Junior, Houston A. 1986. Chicago, University of Chicago Press.

Behrend, Heike. 1998. " Love à la Hollywood and Bombay: Kenyan Postcolonial Studio Photography." Paideuma 44: 139-53.

Bhabha, Homi K. 1994. The Location of Culture. London: Routledge.

Bigham, Elizabeth. 1999. "Issues of Authorship in the Portrait Photographs of Seydou Keita". African Arts 32 (1): 56-67.

Bourdieu, Pierre. 1990. Photography: A Middle-Brown Art. Cambridge: Polity.

Bourne, Samuel. 1866-67. "Narrative of a Photographic Trip to Kashmir (Cashmere) and Adjacent Districts." British Journal of Photography (9 parts; 5 October 1866 to 8 February 1867).

Bryson, Norman. 1983. Vision and Painting: The Logic of the Gaze. New Haven: Yale University Press.

Cadava, Eduardo. 1997. Words of Light: Theses on the Photography of History. Princeton: Princeton University Press.

Carpentier, Alejo. 1995. " The Baroque and the Marvellous Real". In Magical Realism: Theory, History, Community, ed. Lois Parkinson Zamora and Wendy B. Faris. Durham: Duke University Press.

Chakrabarty, Dipesh. 2000. Provincializing Europe: Postcolonial Thought and Historical Difference. Princeton: Princeton University Press.

Chanady, Amaryll. 1995. " The Territorialization of the Imaginary in Latin America: SelfAffirmation and Resistance to Metropolitan Paradigms." In Magical Realism: Theory, History, Community, ed. Lois Parkinson Zamora and Wendy B. Faris. Durham: Duke University Press.

Clifford, James. 1988. "Tell Me about Your Trip: Michel Leiris". In The Pedicament of Culture: Twentieh-Century Ethnograhy, Literature and Art. Cambridge: Harvard University Press.

de Certeau, Michel. 1984. The Practice of Everyday Life. Trans. Steven Rendall. Berkeley: University of California Press. 
de Vries, H. M., ed. c.1928. The Importance of Java as Seen from the Air. Batavia: H. M. de Vries.

Galassi, Peter. 1981. Before Photography: Painting and the Inventions of Photography. New York: Museum of Modern Art.

Gutman, Judith Mara. 1982. Through Indian Eyes: Nineteenth and Early-Twentierh-century Photography from India. New York: Oxford Universyty Press/ International Center for Photograhy.

Heidegger, Martin. 1977. "The age of the World Picture" (1935). In The Question Concerning Technology and Others Essays. Trans. William Lovitt. New York: Harper.

Hershkowitz, Robert.1980. The British Photographer Abroad: The first Thirty Years. London: Thames and Hudson.

Houlberg, Marilyn. 1992. "Haitian Studio Photography: A Hidden World of Images." Aperture 126: 58-65.

Jay, Martin. 1988. "Scopic Regimes of Modernity". In Vision and Visuality, ed. Hal Foster. Seattle: Bay Press.

Krauss, Rosalind E. 1985. "Photography's Discursive Space". In The Originality of the AvantGarde and Other Modernist Myths. Cambridge: MIT Press.

Larkin, Brian. 1997. "Indian Films and Nigerian Lovers: Media and the Creation of Parallel Modernities." Africa 67 (3): 406-40.

Leal, Luis. 1995. "Magical Realism in Spanish American Literature." In Magical Realism: Theory, History, Community, ed. Lois Parkinson Zamora and Wendy B. Faris. Durham: Duke University Press.

MacDougall, David. 1992. "Photo whallahs: An Encounter with photography" In Visual Anthropology Review (outono): 96-100.

Mbembe, Achille. 1992. "The Banality of Power and the Aesthetics of Vulgarity in the Postcolony". Public Culture 4(2).

Mercer, Kobena. 1995. "Home from Home: Portraits from Places In Between". In Self Evident. Birmingham: Ikon Gallery.

Mitchell, Timothy. 1988. Colonising Egypt. Cambridge: Cambridge University Press.

Oguibe, Olu. 1996. "Photography and the Substance of the Image". In In/sight: African Photographers, 1940 to Present. New York: Guggenheim Museum. 


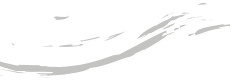

Pinney, Christopher. 1997. " The Nation (Un)pictured? Chromolithography and 'Popular' Politics in Indi, 1978-1995". Critical Inquiry 23(4): 834-67.

1999. "Indian Magical Realism: Notes o Popular Visual Culture". In Subaltern Studies $X$, ed. Gautam Bhadra, Gyan Prakash, and Susie Tharu. Delhi: Oxford University Press.

Ryan, James. 1997. Picturing Empire: Photography and the Visualization of the British Empire. London: Reaktion.

Sontag, Susan. 1979. On Photography. New York: Farrar, Strauss \& Giroux; Harmondsworth, eng:Penguin.

Spittler, Gerd. 1996. “Explorers in Transit: Travels to Tombuku and Agades in the Nineteenth Century". History and Anthropology 9 (2-3).

Sprague, Stephen. F. 1978. "Yoruba Photography: How I See the Yoruba See Themselves". African Arts 12:52-59

Stagl, Justin. 1990. "The Methodising of Travel in the Sixteenth Century: A Tale of Three Cities." History and Anthropology 4 (2): 303-39.

Taussig, Michael, 1986. Shamanism, Colonialism and the Wild Man. Chicago: Chicago University Press.

Tomas, David. 1982. "The Ritual of Photography" Semiotica 40 (1-2): 1-25. 1988. "Towars an Anthropology of Sight: Ritual Performance and the Photographic Process." Semiotica 68 (3-4): 245-70.

Trachtenberg, Alan. 1985. "Albuns of War: On Reading Civil War Photographs". Representations 9.

\section{CHRISTOPHER PINNEY}

Christopher Pinney é Professor de Antropologia e Cultura Visual no University College London. Seus principais interesses estão focados na mídia impressa e na fotografia no sul da Ásia e hinduísmo popular na Índia Central. Atualmente coordena o projeto financiado pelo Conselho Europeu de Investigação "Photodemos / Citizens of Photography". 